\title{
Use of Carbon Nanofibers Loaded With 1-Phenyl-3-Methyl-4-Benzoyl-5-Pyrazone for Preconcentration and Separation of Trace Rare Earth Elements Prior to Their Determination by ICP-MS
}

\author{
Shizhong Chen*, Jianfen Li, Yuanyuan He, and Dengbo Lu \\ College of Chemical and Environmental Engineering, Wuhan Polytechnic University, \\ 68 Xuefu South Road Changqing Garden, Wuhan 430023, P.R. China
}

\section{INTRODUCTION}

In recent years, rare earth elements (REEs) have been attracting more and more attention in industry, including electronics, superconductors, catalysts, and ceramics owing to their specific characteristics. Meanwhile, because they can promote the growth of plants and the body weight gain of animals, REEs are also widely used in agricultural and animal production as microelement fertilizer and feed additives (1-4). As a result, REEs have been discharged and are accumulating in the environment, and finally enter the human body through the food chain from the environmental media such as water, soil, and air (5). Moreover, continuous exposure to low concentrations of REEs could cause adverse health effects because of their bioaccumulation. Chronic exposure to REE dust probably causes occupational pneumoconiosis $(6,7)$. Therefore, the determination of trace / ultra-trace REEs in biological and environmental samples is crucial for public health safety and environmental pollution control.

Due to the very low concentration levels of REEs and complicated matrix effects in biological and environmental samples, an effective separation and preconcentration procedure is usually required prior to their determination. Up to the present, the most commonly used techniques for the separation and

*Corresponding autbor.

E-mail: chenshizbong62@163.com

\section{ABSTRACT}

In this paper, a novel method was developed for the preconcentration, separation, and determination of light (Ce), medium (Eu and $\mathrm{Gd}$ ), and heavy ( $\mathrm{Yb}$ ) rare earth elements (REEs) by inductively coupled plasma mass spectrometry (ICP-MS), based on the adsorption of $\mathrm{Ce}^{3+}, \mathrm{Eu}^{3+}, \mathrm{Gd}^{3+}$, and $\mathrm{Yb}^{3+}$ on carbon nanofibers (CNFs) loaded with 1-phenyl-3methyl-4-benzoyl-5-pyrazone (PMBP). The REEs can be adsorbed quantitatively on CNFs$\mathrm{PMBP}$ in the $\mathrm{pH}$ range of 5.0 to 8.0 and then eluted completely with $1.0 \mathrm{~mol} \mathrm{~L}^{-1} \mathrm{HNO}_{3}$. The experimental parameters for the preconcentration and separation of REEs, such as $\mathrm{pH}$, sample flow rate / volume, eluent concentration / volume, and interfering ions, were examined in detail. Under optimum conditions, the detection limits of this method were found to be $1.5,0.9,0.5$, and $0.3 \mathrm{pg} \mathrm{mL}^{-1}$ for $\mathrm{Ce}, \mathrm{Eu}, \mathrm{Gd}$, and $\mathrm{Yb}$, respectively, and their relative standard deviations were less than $5 \%\left(\mathrm{c}=1.0 \mathrm{ng} \mathrm{mL}^{-1}\right.$, $\mathrm{n}=9$ ). This method has been applied to the determination of trace REEs in a natural water sample and a certified reference material, GBW 07602 (GSV-1) Combined Sample of Shrub Branch and Leaves, with satisfactory results.

preconcentration of trace / ultratrace REEs include coprecipitation, solvent extraction, cloud point extraction, solid phase extraction (SPE), ion exchange, and liquid phase microextraction (8-13).
Among these procedures, SPE has attracted considerable interest in practical applications because of several major advantages: (i) simple to operate, (ii) high concentration factor, (iii) rapid phase separation, and (iv) the ability of combining with different detection techniques (14-16). It is worth noting that in SPE, the adsorbent material plays a fundamentally crucial role in the improvement of selectivity and sensitivity of an analytical method. Recently, an interest in adapting nanometer material as a new adsorbent for the preconcentration and separation of substances has increased significantly because of its special properties. Some nanometer-size materials have been successfully used as SPE adsorbents for the preconcentration / separation of trace / ultra-trace elements and organic compounds (17-25).

Carbon nanofibers (CNFs), as a new type of carbon material, have special surface morphology and steady structure characteristics, which make them a promising candidate as adsorbers. CNFs have been used for hydrogen storage and the separation / preconcentration of trace elements (26-29). In addition, some investigations showed that an important strategy for elemental enrichment is the incorporation of complexing reagents on solid supports (30-34). To the best of our knowledge, however, study of the separation and preconcentration of trace / ultra-trace REEs has received little attention using CNFs loaded with 1-phenyl-3-methyl-4benzoyl-5-pyrazone (PMBP). The purpose of this work was to 
develop a novel method for the separation and preconcentration of trace REEs using a microcolumn packed with CNFs loaded with PMBP before determination by inductively coupled plasma mass spectrometry (ICP-MS). This method was applied to the determination of trace REEs in environmental and biological samples for validation.

\section{EXPERIMENTAL}

\section{Instrumentation}

A Thermo Elemental X-7 ICP-MS (Thermo Elemental Corporation, USA), equipped with a standard low-volume glass impact bead spray chamber, a concentric glass nebulizer and Fassel-type torch, was used for this work. The samples and standards were spiked with $2.0 \mathrm{ng} \mathrm{mL}-1$ of indium (In) internal standard before measurement. The ion lens settings, nebulizer flow rate, and torch position of the instrument were optimized daily in order to obtain the maximum ${ }^{115} \mathrm{In}$ count rate. A Model HL-2 peristaltic pump (Shanghai Qingpu Huxi Instrument Factory, P.R. China), coupled to a self-made polytetrafluoroethylene (PTFE) microcolumn $(20 \mathrm{~mm} \times 3.0 \mathrm{~mm}$ i.d.) packed with CNFs-PMBP, was used for the preconcentration and separation process. A minimum length of PTFE tubing with an i.d. of $0.5 \mathrm{~mm}$ was used for all connections. The $\mathrm{pH}$ values of the solutions were monitored with a $\mathrm{pH}$ meter (Thermo Orion Corporation, USA), supplied with a combined electrode. A Model Ethos T microwave system (Milestone, Italy) was used for sample digestion. The operating parameters for the ICP-MS are listed in Table I.

\section{Standard Solutions and Reagents}

The REE standard solutions (1.0 $\mathrm{mg} \mathrm{mL}^{-1}$ ) were prepared by diluting the stock standard solutions available from the National Analysis Center of Iron \& Steel (Beijing, P.R. China). All reagents used were ultrapure or at least of analytical grade. High purity water obtained from a Milli-Q ${ }^{\circledR}$ A10 system (Millipore Corporation, USA) was used throughout this work. The CNFs were kindly provided by Shenyang Metal Institute of Chinese Academy (Shenyang, P.R. China). Before use, the CNFs were oxidized with concentrated $\mathrm{HNO}_{3}$ according to the literature (35). The treated CNFs were dried at $100{ }^{\circ} \mathrm{C}$ and stored for future use.

\section{Column Preparation with PMBP}

Twenty milligrams of the treated CNFs was introduced into a PTFE microcolumn $(20 \mathrm{~mm} \times 3.0 \mathrm{~mm}$ i.d.) plugged with a small portion of glass wool at both ends by a dry packing method. Before use, 1.0 mol L-1 $\mathrm{HNO}_{3}$ solution and high purity water were passed through the column to clean it. Then, the column was washed with high purity water to $\mathrm{pH}$ 7.0. Finally, $1.0 \times 10^{-4} \mathrm{~mol} \mathrm{~L}^{-1} \mathrm{PMBP}$ solution was passed through the column at a flow rate of $0.2 \mathrm{~mL} \mathrm{~min}{ }^{-1}$. The filtrate was collected and analyzed for un-adsorbed PMBP with a UV-Vis spectrophotometer at $273 \mathrm{~nm}$. According to the calculation, the retained amount of $\mathrm{PMBP}$ on the CNFs was $0.56 \mathrm{mg} \mathrm{g}^{-1}$.

\section{Atomic Spectroscopy 1 Vol. 37(3), May/June 2016}

\section{Sample Pretreatment}

A natural water sample, collected from Dongxi Lake (Wuhan, P.R. China), was filtered through a $0.22-\mu \mathrm{m}$ membrane filter and analyzed as soon as possible after sampling.

A portion $(0.5000 \mathrm{~g})$ of sample (combined sample of shrub branch and leaves) was accurately weighed into a 100-mL PTFE vessel to which $8.0 \mathrm{~mL}$ of concentrated $\mathrm{HNO}_{3}$ and $2.0 \mathrm{~mL}$ of $\mathrm{H}_{2} \mathrm{O}_{2}(35 \%, \mathrm{~m} / \mathrm{v})$ were added. The vessel was placed onto a microwave turntable. The sample was digested in the microwave oven at $180{ }^{\circ} \mathrm{C}$ (conditions obtained by a preliminary experiment: ramp, 15 minutes; hold, 30 minutes) with a power of $1.0 \mathrm{~kW}$. After that, the sample solution was cooled to room temperature. The obtained solution was transferred into a 50-mL PTFE beaker, and the vessel rinsed with about $10 \mathrm{~mL}$ of high purity water, which was added to the beaker. The solution was then heated to near dryness. The residues were dissolved in $2.0 \mathrm{~mL}$ of 0.1 mol L-1 $\mathrm{HNO}_{3}$ solution, then diluted to the desired volume with high purity water. The $\mathrm{pH}$ value of the resultant solution was kept at 6.0 with $1.0 \mathrm{~mol} \mathrm{~L}^{-1} \mathrm{HNO}_{3}$. The blank was prepared in exactly the same way as the sample.

TABLE I

Instrumental Operating Parameters for ICP-MS

\begin{tabular}{ll}
\hline Plasma Power & $1.3 \mathrm{k} \mathrm{W}$ \\
Plasma Argon Flow Rate & $14 \mathrm{~L} \mathrm{~min}^{-1}$ \\
Auxiliary Argon Flow Rate & $0.72 \mathrm{~L} \mathrm{~min}^{-1}$ \\
Nebulizer Argon Flow Rate & $0.91 \mathrm{~L} \mathrm{~min}^{-1}$ \\
Sampler Orifice (Ni) & $1.1 \mathrm{~mm}$ \\
Skimmer Orifice (Ni) & $0.7 \mathrm{~mm}$ \\
Acquisition Mode & Peak Jumping \\
Number of Sweep & 100 \\
Dwell Time & $10 \mathrm{~ms}$ \\
Acquisition Time & $40 \mathrm{~s}$ \\
Number of Measurements per Peak & 3 \\
Isotopes & $139 \mathrm{Ce},{ }^{140} \mathrm{Eu},{ }^{153} \mathrm{Gd},{ }^{172} \mathrm{Yb}$ and ${ }^{115} \mathrm{In}$ \\
\hline
\end{tabular}




\section{Procedure}

In order to study the adsorption of REEs under dynamic conditions, a portion of aqueous sample solution containing REEs was prepared, and the sample $\mathrm{pH}$ was adjusted to a desired value with $\mathrm{HNO}_{3}$ and $\mathrm{NaOH}$ solutions. The solution was passed through the column by using a peristaltic pump at the desired flow rate. Afterwards, the retained REE ions were eluted with $2.0 \mathrm{~mL}$ of $1.0 \mathrm{~mol} \mathrm{~L}^{-1} \mathrm{HNO}_{3}$. The analytes in the effluents were determined by ICP-MS. The column could be used repeatedly after regeneration with $1.0 \mathrm{~mol} \mathrm{~L}^{-1} \mathrm{HNO}_{3}$ and high purity water, respectively. The recovery of REEs was calculated from the ratio of the concentration found by ICP-MS to that of the initial sample.

\section{RESULTS AND DISCUSSION}

\section{Effect of pH on Adsorption}

Due to its effects on the formation of the REEs-PMBP chelating compound and the surface speciation of an adsorbent, the sample $\mathrm{pH}$ plays an important role in the SPE step. For this purpose, the $\mathrm{pH}$ values of the sample solutions were adjusted to a range of 1.0-8.0 with $\mathrm{HNO}_{3}$ or $\mathrm{NaOH}$ solution. Figure 1 shows that the analytes were absorbed much better at the $\mathrm{pH}$ range of 5.0-8.0 with recoveries over $90 \%$. Therefore, a $\mathrm{pH}$ of 6.0 was used as a compromise condition in this work.

\section{Influence of Eluent Concentra- tion and Its Volume}

The eluent is an important parameter in the SPE process which can influence the enrichment performance because it determines whether or not the analytes are completely eluted from an adsorbent. From Figure 1 it can be seen that the adsorption of REEs on CNFs-PMBP could be negligible at $\mathrm{pH}<1$.0. For this reason, various concentrations of $\mathrm{HNO}_{3}$ were studied for desorption of the retained REEs from the microcolumn. The experimental results in Table II indicate that $1.0 \mathrm{~mol} \mathrm{~L}^{-1} \mathrm{HNO}_{3}$ was sufficient for the complete elution of the analytes.

In addition, the effect of eluent volume on the recovery of the analytes was investigated by keeping the $\mathrm{HNO}_{3}$ concentration at 1.0 mol L $\mathrm{L}^{-1}$. It was found that quantitative recoveries (>90\%) could be obtained with $1.0 \mathrm{~mL}$ of $1.0 \mathrm{~mol} \mathrm{~L}^{-1}$. Taking the required sampling volume for ICP-MS into account, 2.0 $\mathrm{mL} \mathrm{HNO}_{3}$ was adopted as the eluent throughout the experiment.

\section{Choice of Sample Flow Rate}

The sample flow rate through the column packed with CNFs-

TABLE II

Effect of Eluent Concentration on the Recovery of the Analytes

\begin{tabular}{ccccc}
\hline $\begin{array}{c}\text { Concentration } \\
\left(\mathrm{HNO}_{3}, \mathrm{~mol} \mathrm{~mL}^{-1}\right)\end{array}$ & $\mathrm{Ce}^{3+}$ & \multicolumn{2}{c}{ Recovery(\%) } \\
\hline 0.1 & 32.1 & 29.8 & 35.12 & 40.1 \\
0.2 & 48.2 & 45.4 & 50.2 & 58.4 \\
0.5 & 65.4 & 72.6 & 82.1 & 69.8 \\
1.0 & 98.6 & 94.5 & 95.7 & 96.7 \\
1.5 & 95.2 & 97.1 & 96.3 & 94.5 \\
2.0 & 94.5 & 99.2 & 101 & 98.7 \\
\hline
\end{tabular}

PMBP is another important factor that influences the enrichment efficiency. For the sake of achieving better enrichment, a series of experiments ranging from $0.2-2.0$ $\mathrm{mL} \mathrm{min}^{-1}$ were designed for obtaining the optimal flow rate by passing $20 \mathrm{~mL}$ of sample solution through the microcolumn with a peristaltic pump. The results in Figure 2 show that there was no decrease of extraction performance in the range between 0.2 and $1.0 \mathrm{~mL} \mathrm{~min}^{-1}$, and all the recoveries were over $90 \%$. However, the recoveries of the analytes decrease by further increasing the flow rate above $1.0 \mathrm{~mL} \mathrm{~min}^{-1}$ because of a decrease in adsorption kinetics. Thus, a flow rate of $\mathbf{1 . 0}$ $\mathrm{mL} \mathrm{mim}^{-1}$ was selected as the optimal flow rate for further study.

\section{Optimization of Sample Solution Volume}

The sample solution volume significantly affects the SPE performance due to its influence on the enrichment factor and the detection limit. In the present work, a series of experiments ranging from 20-300 mL of sample solutions containing 1.0 ng REE ions were carried out. The results showed that quantitative recoveries (>90\%) were obtained for a sample volume up to $200 \mathrm{~mL}$. However, the recoveries of the analytes decreased with increasing sample volume above $200 \mathrm{~mL}$. Because the elution volume was $1.0 \mathrm{~mL}$, an enrichment factor of 200 could be obtained for the analytes.

\section{Adsorption Capacity}

Adsorption capacity is an important parameter usually adopted for the performance evaluation of the adsorbent. It was investigated by the method reported in the literature (36). Aliquots of $20 \mathrm{~mL}$ of a series of concentrations (10-35 $\mu \mathrm{g} \mathrm{mL}{ }^{-1}$ ) were adjusted to the appropriate $\mathrm{pH}$, then preconcentrated and eluted. The amount of the analytes adsorbed at each con- 


\section{Atomic Apectroscopy \\ Vol. 37(3), May/June 2016}

centration level was determined. Breakthrough curves were obtained by plotting the metal ion concentration versus the amount of metal ions adsorbed on per gram of adsorbent. The adsorption capacities calculated from the breakthrough curve were 21.5, 23.2, 19.3, and $23.0 \mathrm{mg} \mathrm{g}^{-1}$ for $\mathrm{Ce}, \mathrm{Eu}, \mathrm{Gd}$, and $\mathrm{Yb}$, respectively.

\section{Interference of Diverse Ions}

In order to assess the possible use of this separation and preconcentration method for the analysis of a real sample with a complicated matrix, the effects of diverse ions on the adsorption of the analytes were investigated. The tolerance limit of diverse ions is defined as the largest amount making the recovery of the analyte less than $90 \%$. In these experiments, the interfering ion concentrations were varied, whereas the concentrations of the analytes were kept at 0.5 $\mathrm{ng} \mathrm{mL}^{-1}$. The effects of interfering ions on the recoveries of the analytes are presented in Table III. It can be seen that the presence of major cations and anions has no obvious influence on the adsorption of the analytes under the selected conditions.

\section{Detection Limits and Precision}

According to the definition of IUPAC, the detection limit is defined as the concentration corresponding to three times the standard deviation of the blanks. Under the optimum conditions, the detection limits for $\mathrm{Ce}, \mathrm{Eu}, \mathrm{Gd}$, and $\mathrm{Yb}$ were found to be $1.5,0.9,0.5$, and $0.3 \mathrm{pg} \mathrm{mL}^{-1}$, respectively. The preci- sions for $\mathrm{Ce}, \mathrm{Eu}, \mathrm{Gd}$, and $\mathrm{Yb}$, expressed as relative standard deviations, were $3.7,2.8,4.5$, and $4.1 \%$, respectively $\left(\mathrm{n}=9, \mathrm{c}=1.0 \mathrm{ng} \mathrm{mL}^{-1}\right)$.

\section{Application to Real Samples}

This method was applied to the determination of $\mathrm{Ce}, \mathrm{Eu}, \mathrm{Gd}$, and $\mathrm{Yb}$ in a natural water sample, and the recoveries of spike experiments were also studied. The obtained results are summarized in Table IV. Additionally, the accuracy of this method was examined by analyzing the certified reference material (CRM) GBW 07602 (GSV-1) Com-

TABLE III

Effects of Diverse Ions

\begin{tabular}{lc}
\hline Coexisting Ion & Concentration Ratio \\
\hline $\mathrm{Na}^{+}, \mathrm{K}^{+}$ & 50,000 \\
$\mathrm{Ca}^{2+}, \mathrm{Mg}^{2+}$ & 20,000 \\
$\mathrm{Al}^{3+}, \mathrm{Fe}^{3+}$ & 500 \\
$\mathrm{SiO}_{3}{ }^{2-}, \mathrm{SO}_{4}{ }^{2-}, \mathrm{PO}_{4}{ }^{3-}$ & 20,000 \\
\hline
\end{tabular}

${ }^{a}$ Concentration ratio: Foreign ion / REEs ${ }^{3+}$

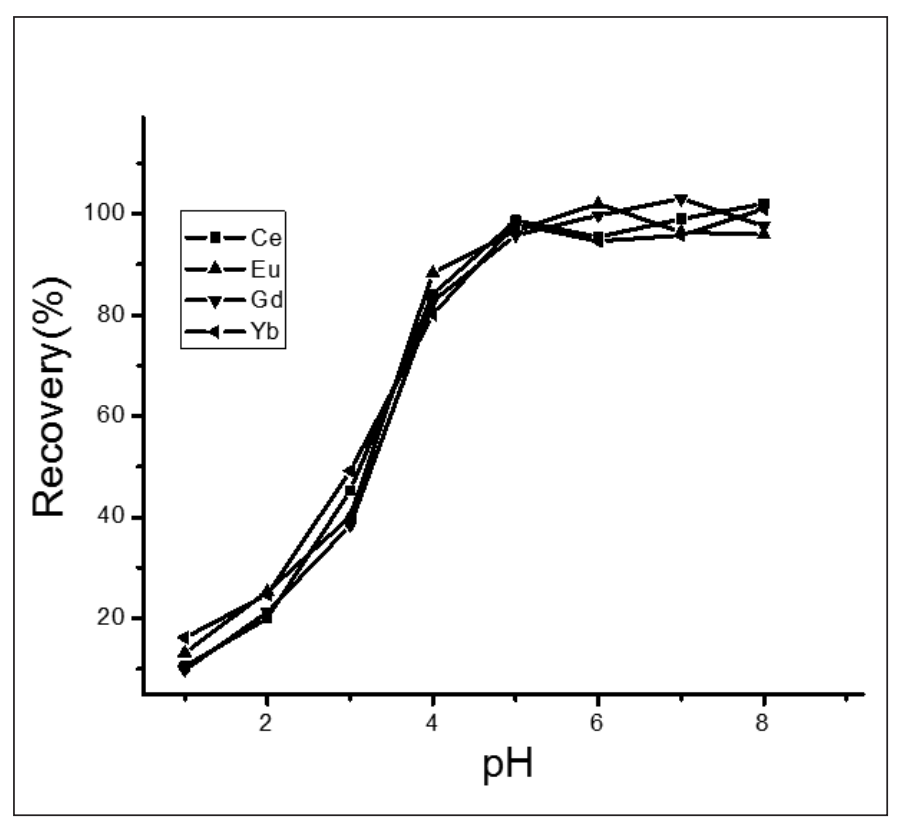

Fig. 1. Effect of $p H$ on the adsorption of the analytes on CNFs-PMBP. REEs: $0.5 \mathrm{ng} \mathrm{mL}^{-1}$; sample volume: $20 \mathrm{~mL}$.

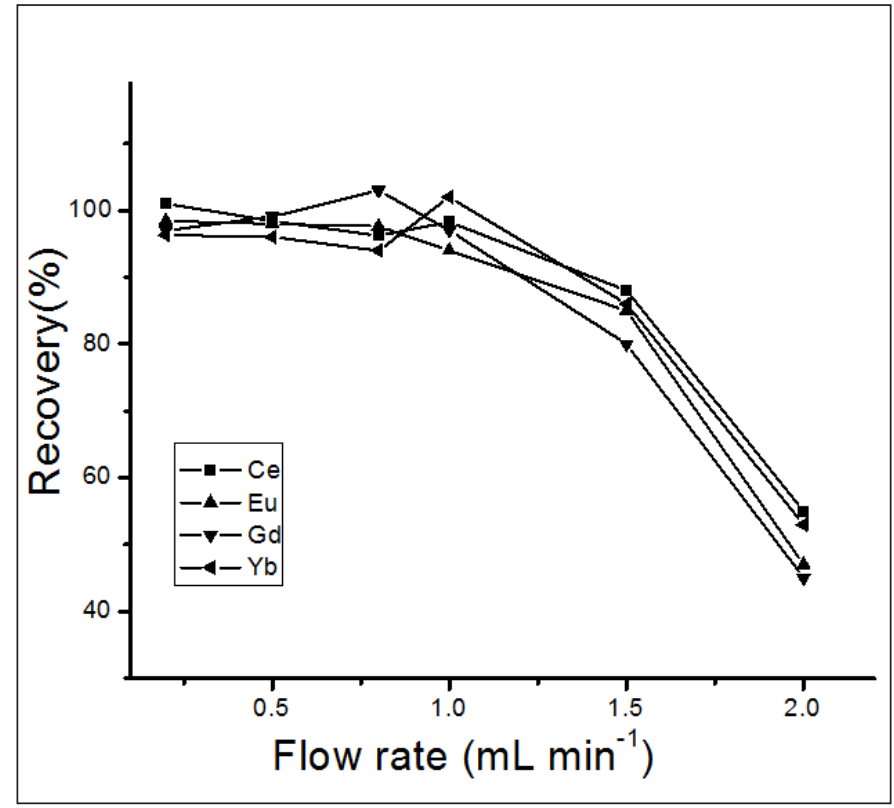

Fig. 2. Effect of sample flow rate on the recovery of the analytes on CNFs-PMBP. REEs: $0.5 \mathrm{ng} \mathrm{mL}^{-1} ; \mathrm{pH}=6.0$; sample volume: $20 \mathrm{~mL}$. 
bined Sample of Shrub Branch and Leaves (China National Center for Standard Materials, P.R. China), and the results are listed in Table V. As can be seen from Table $\mathrm{V}$, the determined values were in good agreement with the certified values.

\section{CONCLUSION}

In summary, a novel method was developed for the separation and preconcentration of trace REEs by a microcolumn packed with CNFs loaded with PMBP prior to their determination by ICP-MS. The adsorption behaviors of the analytes were investigated systematically. The analytes retained on the microcolumn can be easily desorbed with $1.0 \mathrm{~mol} \mathrm{~L}^{-1} \mathrm{HNO}_{3}$ solution, and no carryover was observed in the next analysis. An enrichment factor of 200 was achieved. It is worth noting that this method, based on the incorporation of chelating reagents in solid supports, not only has excellent anti-interference ability, but it also improves the analytical performance. It is likely to become a very effective method for the determination of trace / ultra-trace elements and their speciation in a complex matrix sample.

\section{ACKNOWLEDGMENT}

The authors are grateful for the financial support of the Special Fund for Agroscientific Research in the Public Interest (Project No. 201503135-22)

Received December 4, 2015

\section{REFERENCES}

1. R.A. Lagad, D. Alamelu, A.K. Chaudhary, and S.K. Aggarwal, At. Spectrosc. 33(4), 109 (2012).

2. X. Pang, D. Li, and P. Peng, Environ. Sci. Pollut. Rev. 9, 143 (2002).

3. A. Premadas, At. Spectrosc. 33(1), 14 (2012).

4. S. Buckingham, J. Maheswaran, B. Meehan, and K. Peverill, Mater. Sci. Forum 315, 339 (1999).

5. H. Zhu, Q. Wu, T. Fan, Q. Liu, and W. Zhang, J. Radiol. Prot. 28, 573 (2008).

6. S. Hirano and K.T. Suzuki, Environ. Health Perspect. 104, 85 (1996).

7. Z.Y. Chen and X.Z. Zhu, J. Ecol. Rural Environ. 24, 88 (2008).

8. S. Chen, Metall. Anal. 26(3), 7 (2006).
9. N. Freslon, G. Bayon, D. Birot, C. Bollinger, and J.A. Barrat, Talanta 85, 582 ( 2011).

10. S. Chen, Y. He, D. Lu, and X. Guo, At. Spectrosc. 34(3), 73 (2013).

11. Y. Li and Bin Hu, J. Hazard. Mater. 174, 534 ( 2010).

12. S. Chen, S. Zhu, and D. Lu, At. Spectrosc. 35(1), 1 (2014).

13. S. Asai and A. Limbeck, Talanta 135 , 41 (2015).

14. K. Pyrzynska, Crit. Rev. Anal. Chem. 29, 313 (1999).

15. V. A. Lemos, L. S. G. Teixeira, M. A. Bezerra, A. C. S. Costa, J. T. Castro, L. A. M. Cardoso, D. S. de Jesus, E. S. Santos, P. X. Baliza, and L. N. Santos, Appl. Spectrosc. Rev. 43, 303 (2008)

16. S. Chen, C. Liu, D. Lu, and L. Zhu, At. Spectrosc. 30(1), 20 (2009).

17. Q. Zhou, X. Zhao, G. Xie, and J. Xiao, At. Spectrosc. 29(4), 145 (2008).

18. S. Chen, S. Zhu, Y. He, and D. Lu, Food Chem. 150, 254 (2014).

19. M.A. Habila, Z.A. Alothman, and M. Soylak, At. Spectrosc. 36(3), 146 (2015).

20. G. H. Liu, Y. F. Zhu, X. R. Zhang, and B. Q. Xu, Anal. Chem. 74(24), 6279 (2002).

21. W. Hong, W. Hongyu, H. Baoping, D. Baixiang, L. Jusheng, and T. Jiuying, Microchim. Acta 166(1-2), 41(2009).

TABLE IV

Analytical Results of Analytes in Natural Water Sample

\begin{tabular}{cccc}
\hline Element & $\begin{array}{c}\text { Added } \\
\left(\mathrm{ng} \mathrm{mL}^{-1}\right)\end{array}$ & $\begin{array}{c}\text { Found }^{\mathrm{a}} \\
\left(\mathrm{ng} \mathrm{mL}^{-1}\right)\end{array}$ & $\begin{array}{c}\text { Recovery } \\
(\%)\end{array}$ \\
\hline $\mathrm{Ce}$ & 0 & $2.81 \pm 0.15$ & - \\
& 3.0 & $5.67 \pm 0.32$ & 95.3 \\
\hline $\mathrm{Eu}$ & 0 & $0.094 \pm 0.005$ & - \\
& 1.0 & $1.08 \pm 0.09$ & 98.6 \\
\hline $\mathrm{Gd}$ & 0 & $0.065 \pm 0.004$ & - \\
& 1.0 & $1.09 \pm 0.07$ & 103 \\
\hline $\mathrm{Yb}$ & 0 & $1.26 \pm 0.10$ & - \\
& 1.0 & $2.27 \pm 0.14$ & 101 \\
\hline
\end{tabular}

${ }^{a}$ Mean value \pm standard deviation, $n=3$.

\begin{tabular}{ccc} 
TABLE V & \multicolumn{2}{c}{$\begin{array}{c}\text { Analytical Results of Analytes in CRM } \\
\text { GBW 07602 (VGS-1) Combined Sample } \\
\text { of Branch and Leaves of Shrub }\end{array}$} \\
\hline Element & $\begin{array}{c}\text { Found }^{\mathrm{a}} \\
\left(\mu \mathrm{g} \mathrm{g}^{-1}\right)\end{array}$ & $\begin{array}{c}\text { Certified } \\
\left(\mu \mathrm{g} \mathrm{g}^{-1}\right)\end{array}$ \\
\hline $\mathrm{Ce}$ & $2.6 \pm 0.1$ & $2.4 \pm 0.2$ \\
$\mathrm{Eu}$ & $0.042 \pm 0.003$ & $0.037 \pm 0.002$ \\
$\mathrm{Gd}$ & $0.023 \pm 0.002$ & - \\
$\mathrm{Yb}$ & $0.071 \pm 0.004$ & $0.063 \pm 0.011$ \\
\hline
\end{tabular}

${ }^{a}$ Mean value \pm standard deviation, $n=3$. 


\section{A Spectroscopy $_{\text {pec }}^{\text {tomich }}$ \\ 1 Vol. 37(3), May/June 2016}

22. Y. Wu, J. Zhang, J. Liu, Z. Deng, M. Han, F. Jiang, D. Wang, H. Wang, and $\mathrm{H}$. Yuan, At. Spectrosc. 32(1), 41 (2011).

23. R. Yinzhe, F. Zhefeng, and W. Jianying, Microchim. Acta 158 (3-4), 227 (2007).

24. W. Tian and Z. Fan, At. Spectrosc. 33(1), 1 (2012).

25. M. Behbahani, A. Bagheri, M. Taghizadeh, M. Salarian, O. Sadeghi, L. Adlnasab, and K. Jalali, Food Chem. 138(2-3), 2050 (2013).

26. A. Chambers, C. Park, R. T. K. Baker, and N. M. Rodriguez, J. Chem. Phys. B 102(22), 4253 (1998).

27. Y. He, S. Chen, X. Zhou, and X. Wang, At. Spectrosc. 33(4), 117 (2012).

28. S. Chen, M. Xiao, D. Lu, and X. Zhan, Rapid Comm. Mass Spectrom. 21, 2524 (2007).

29. S. Chen, X. Zhan, D. Lu, and C. Liu, At. Spectrosc. 29(4), 124 (2008).

30. S. Chen, Y. He, Y. Zhang, and D. Lu, At. Spectrosc. 36(4), 153 (2015).

31. E.M. Soliman, M.B. Saleh, and S.A. Ahmed, Anal. Chim. Acta 523, 133 (2004).

32. M. Tuzen, K.O. Saygi, and M. Soylak, J. Hazard. Mater. 632, 152 (2008).

33. M. Ghaedi, A. Shokrollahi, A.H. Kianfar, A. Pourfarokhi, N. Khanjari, A.S. Mirsadeghi, and M. Soylak, J. Hazard. Mater. 162, 1408 (2009).

34. G. Kaya, I. Akdeniz, and M. Yaman, At. Spectrosc. 29(4), 150 (2009).

35. P. V. Lakshiminarayanan, H. Toghiani, and C. U. Pittman Jr, Carbon 42, 2433 (2004)

36. A. Maqieira, H.AM. Elmahadi, and R. Puchades, Anal. Chem. 66, 3632 (1994). 